\title{
EARTHQUAKE RESISTANCE OF REINFORCED CONCRETE SHELLS OF DIVERSE FORMS IN THE PLANE AND WITH DIFFERENT CONTOURS
}

\author{
MOSHE DANIELI ${ }^{1} \&$ ARCADY ARONCHIK ${ }^{2}$ \\ ${ }^{1}$ Department of Civil Engineering, Ariel University, Israel \\ ${ }^{2}$ Anatoly Borushansky Engineering, Jerusalem, Israel
}

\begin{abstract}
In this study, we present the earthquake resistance of three types of reinforced concrete shells, having three different plans and contours. In the Memorial Museum near the city of Karachaevsk, Israel, a reinforced concrete monolithic shell serves as the building's roof and fence. The middle surface of the building is a connected shell in the form of a revolution and truncated cone, with a spherical segment. The shell on the perimeter rests on the foundation beam. In the market in the city of Sukhumi, Republic of Georgia, a precast monolithic spherical reinforced concrete shell square overlaps the Central Hall. Contour diaphragms are made of steel trusses transmitting the load to monolithic reinforced concrete columns. In Borjomi, Israel, the roof of a pump room is made of a monolithic triangular reinforced concrete spherical shell whose corners are supported in the corners on points. Three bowstring arches, connected to a support, border the shell's contour. The results of theoretical and full-scale experimental analyses of the static and dynamic characteristics of these shells are presented. Theoretical analysis was performed by means of the Finite Element Method (FEM). We show that all three constructions have the required degree of seismic resistance, yet shells with stiffer and more rounded contours exhibit better behavior under seismic conditions.

Keywords: concrete shell, construction, contours, diaphragm shapes, earthquake resistance, finite element method, modal linear analysis, reinforced concrete, shells, steel trusses.
\end{abstract}

\section{INTRODUCTION}

Various forms of shells are widely used in the construction of civil and industrial buildings. The first large roof known is a stone dome. Currently there are many stone domes all over the world that are now considered architectural works of art, and whose preservation is a societal responsibility. With the appearance of concrete in the late nineteenth century, the use of more lightweight concrete domes replaced heavy stone domes. Reinforced concrete shells of various forms were consequently developed, which became an effective kind of spatial coverage in the twentieth century.

The widespread use of concrete shells as roofs began in Germany and gradually spread to other countries in Europe, the US and Japan. Originally, reinforced concrete shells typically had a maximum span of $20 \mathrm{~m}$ and an effective thickness of a minimum of $10-15 \mathrm{~cm}$ : These were implemented of monolithic reinforced concrete on solid, mostly wooden, framework. Although today there are reinforced concrete shells with a span of over $200 \mathrm{~m}$, the most common coverings worldwide have a span between $20 \mathrm{~m}$ and $60 \mathrm{~m}$.

The first concrete dome known to the author, built in the Republic of Georgia, is a spherical monolithic concrete dome atop the hall of the synagogue of Ashkenazi Jews in Tbilisi (now the D. Baazow historical-ethnographic museum of Georgian Jews). The dome was built in 1915 (span of dome, $15 \mathrm{~m}$; rise $\mathrm{f}=7.0 \mathrm{~m}$; thickness $t=0.15-0.2 \mathrm{~m}$ ) [1]. Since 1940, monolithic reinforced concrete shells with relatively small spans have been widely constructed in the Republic of Georgia. Since the 1950s, more than 40 precast shells have been constructed there [1]. 
One of this paper's authors participated in full-scale experiments on a number of monolithic concrete shells. In this paper, we present the results of experiments involving the following [2]-[5]:

1. The reinforced concrete monolithic shell which serves as a roof and fence of the Memorial Museum adjacent to the city of Karachaevsk, in Caucasus, Russia, which was built

1967-1968. The middle surface of the shell is a connected shell of a revolution in the form of a truncated cone with a spherical segment. The shell on the perimeter leans on the foundation beam. The shell was designed by the Giprogorstroi Design Institute of the Republic of Georgia and the Institute of Structural Mechanics and Earthquake of the Georgian Academy of Sciences [2], [3].

2. A square precast monolithic spherical reinforced concrete shell overlapping the central hall of the new market erected in the city of Sukhumi, Republic of Georgia in 19781980. The shell was designed by the Institute of Structural Mechanics and Earthquake of the Georgian Academy of Sciences and the Department of Giprotorg of the Republic of Georgia, as well as the Design Institute No. 1 of Leningrad, Russia [1], [4].

3. The roof of a pump room, in Borjomi, Republic of Georgia, built in 1965-1966. The roof is made of monolithic reinforced concrete. The triangular spherical shell is supported in the corners. Three bowstring arches, connected among themselves in the support, border the shell as a contour. The shell was designed by the Giprogorstroi Design Institute and the Institute of Structural Mechanics and Earthquake of the Georgian Academy of Sciences, Republic of Georgia [5].

The shells are located in different seismic regions of the Caucasus. The expected horizontal acceleration of the ground for these regions is $\boldsymbol{a}_{\boldsymbol{h} \text {, } \max }=0.75 \div 2.00 \mathrm{~m} / \mathrm{s}^{2}$. It is important to mention that in 1970 the Borjomi shell successfully overcame the seismic effects of a ground horizontal acceleration of $\boldsymbol{a}_{\boldsymbol{h}, \max }=1.0 \mathrm{~m} / \mathrm{s}^{2}$ (1970 Borjomi earthquake) [2].

The shells differ in plan and contour. A series of studies was conducted on site to estimate the static and dynamic characteristics of shells. The main results of these studies and investigations are presented in [1]-[5]. Some results of these studies were used in this article. The aim of the present work was to examine these three types shells, using static and dynamic modal linear analysis. Data for the structural models (geometry, load, etc.) were taken from structural sketches and drawings, presented in other references [1]-[5]. According to the numerical analysis of seismic actions, displacement ratios and stresses are lower than the maximum permitted levels, for all three shells; therefore, we conclude that all three constructions have sufficient seismic resistance. However, shells with stiffer and more rounded contours exhibit better seismic behavioral responses.

A series of static and dynamic modal linear analyses on all three models was performed using the FEM (Finite Element Method) on LIRA and STR (Ukraine and France) software certified by CONCEIL (June, 1992). All three structural models consisted of several groups of three-dimensional (3D) finite elements: shells, bars and springs. The damping ratio used in all three numeral models was $\zeta=0.10$.

Information on the dynamic characteristics of shells is presented in many referenced and unreferenced sources [6]-[9]. 


\section{MONOLITIC REINFORCED CONCRETE SHELL OF REVOLUTION}

\subsection{Structure of shell of revolution}

The Memorial Museum for the Heroes and Defenders of the Caucasus Passes, near the city of Karachaevsk, Russia, is a reinforced concrete monolithic shell, built in 1967-1968.

Fig. 1 shows that the shell serves as the building's roof and fence [2], [3]. The middle surface of the building is a connected shell of revolution in the form of a truncated cone with a spherical segment. The diameter of the resting contour is $21.74 \mathrm{~m}$, the spherical segment is $19.65 \mathrm{~m}$, the thickness of the conical section is $10 \mathrm{~cm}$ and the thickness of the spherical section is $8 \mathrm{~cm}$. The building is $6.9 \mathrm{~m}$ high, the height of its walls is $4.2 \mathrm{~m}$, and the rise of the spherical segment is $1.6 \mathrm{~m}$. On the perimeter, the shell leans on the foundation beam. The main geometrical dimensions are presented in Fig. 2. Where the spherical and conical sections meet, the shell thickness increases to $20 \mathrm{~cm}$.

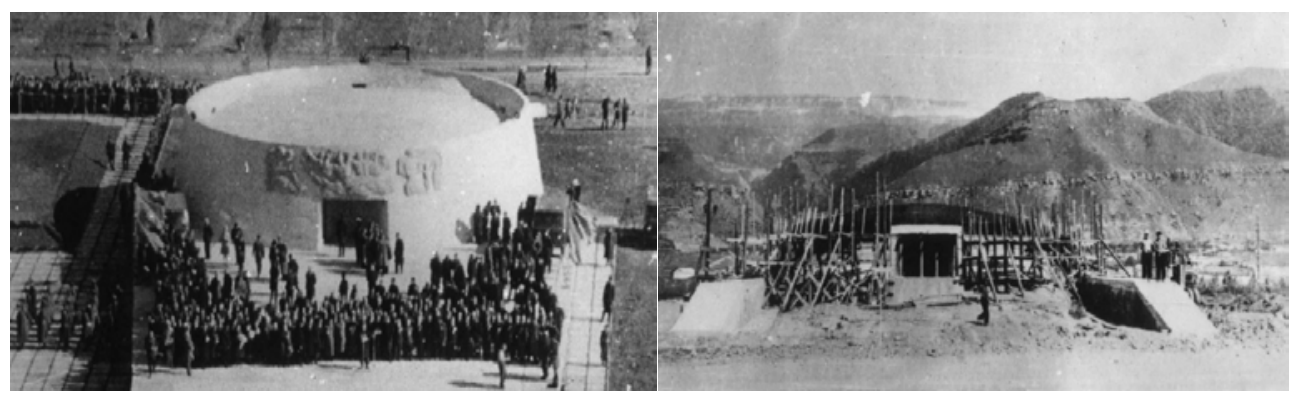

(a)

(b)

Figure 1: The Memorial Museum near Karachaevsk, Russia. (a) A general view; and (b) View while under construction.

\subsection{Structural analysis}

\subsubsection{Static study}

The museum structure was designed using the membrane theory of shells, taking into account the boundary effect, and the theory of limit analysis on the basis of the three-parameter axisymmetric mechanism of plastic collapse [3], [10]. The design grade of concrete is M 30.

\subsubsection{Study of the dynamic characteristics}

The dynamic characteristics of reinforced concrete structures were studied by analytic and numerical calculations. The dynamic characteristics of natural oscillations were determined theoretically, according to other's publications [11]. The results were a frequency $f=18.86 \mathrm{~Hz}$ and a period $\mathrm{T}=0.053 \mathrm{~s}$, referring exclusively to the spherical segments without the conicalshaped surface. The main results of structural dynamic numerical analysis in the horizontal earthquake direction are provided in another publication [12].

For the simulations, we selected three modes $(1,47,88)$ of natural vibrations for these forms that demonstrate characteristic mode shapes. The results of our simulations for the Museum building are shown in Fig. 3. The displacements, contour of normal stress and bending moments for these forms of the Museum are shown in Table 1. 

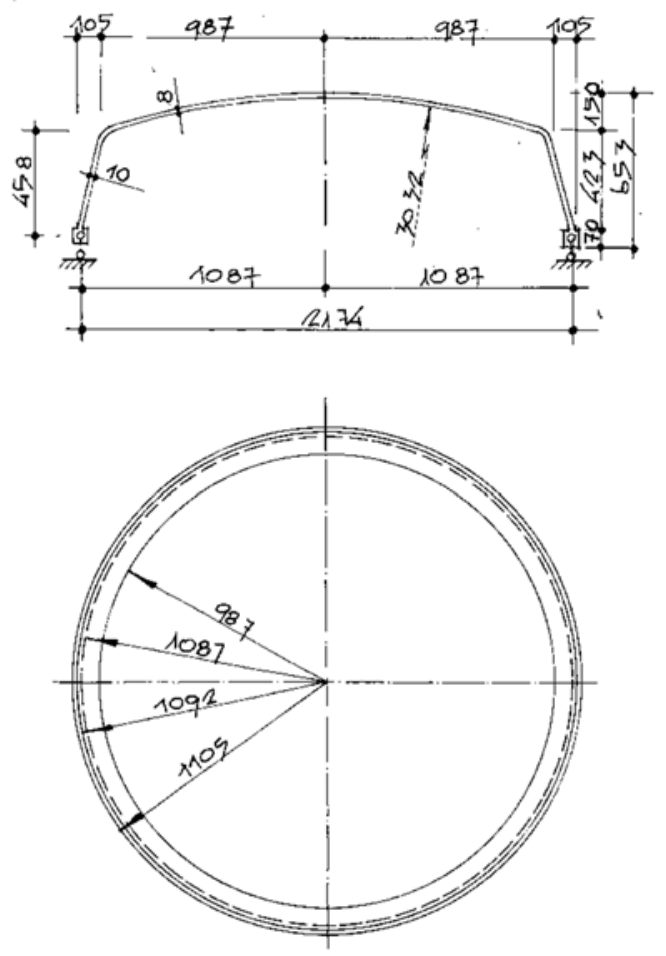

Figure 2: The Memorial Museum near Karachaevsk, Russia. Top image: Meridian section; bottom image: Plan (Unit: $\mathrm{cm}$ ).

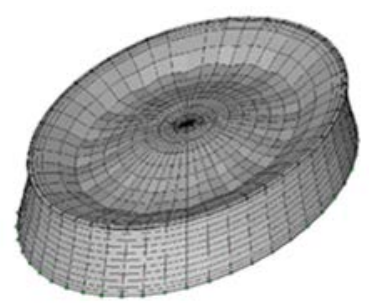

(a)

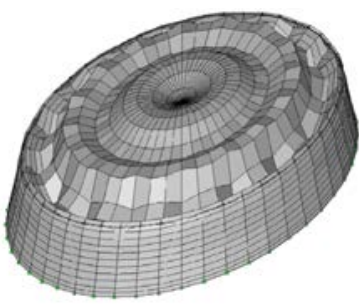

(b)

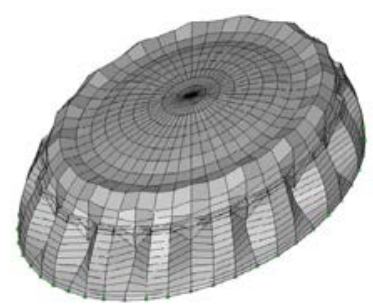

(c)

Figure 3: Mode shapes of natural vibrations of the museum structure. Earthquake direction: vertical. (a) Mode shape 1; (b) Mode shape 47; and (c) Mode shape 88.

Frequencies for the first six modes of natural vibration (mode shapes) according to known studies are $[13]: f_{1}=8.82 \mathrm{~Hz} ; f_{2}=10.82 \mathrm{~Hz} ; f_{3}=10.32 \mathrm{~Hz} ; f_{4}=12.03 \mathrm{~Hz} ; f_{5}=12.62 \mathrm{~Hz} ;$ and $f_{6}$ $=13.97 \mathrm{~Hz}$. These frequencies are for spherical segments with the cone surface.

Notably, the calibration of numerical models was not the aim of these numerical analyses. The structure itself clearly includes several groups of elements that were not presented in the numerical model given (which focused exclusively on masses). The geometry, characteristics of materials, and loads were based on information taken from the actual structures. 
Table 1: Main results of structural analysis of Museum: Maximum values.

\begin{tabular}{|c|c|c|c|c|}
\hline \multirow{2}{*}{ Parameters } & \multicolumn{3}{|c|}{ Seismic loads } & \multirow{2}{*}{$\begin{array}{c}\text { Experimental } \\
\text { shape }\end{array}$} \\
\hline & Shape 1 & Shape 47 & Shape 88 & \\
\hline $\begin{array}{l}\text { Periods of natural } \\
\text { vibrations, } \mathrm{s}: \mathrm{T}_{1}=0.1688 \\
\mathrm{~T}_{2}=0.1416 ; \mathrm{T}_{3}=0.1388\end{array}$ & 0.1688 & 0.0598 & 0.0208 & $0.0699 *$ \\
\hline Base force $F(h, z), t$ & 9.49 & 1.78 & 6.71 & \\
\hline $\begin{array}{l}\text { Max. displacement, mm } \\
\text { Vertical, w } \\
\text { Horizontal, u }\end{array}$ & $\begin{array}{l}0.559 \\
0.085\end{array}$ & $\begin{array}{l}0.043 \\
0.011\end{array}$ & $\begin{array}{l}0.014 \\
0.088\end{array}$ & \\
\hline $\begin{array}{c}\text { Maximum stress, MPa } \\
\sigma_{\mathrm{Ny}}(+) / \sigma_{\mathrm{Ny}}(-) \\
\sigma_{\mathrm{My}}(+) / \sigma_{\mathrm{My}}(-)\end{array}$ & $\begin{array}{l}0.210 / 0.160 \\
0.083 / 0.072\end{array}$ & & & \\
\hline
\end{tabular}

\subsection{Full-scale experiment}

\subsubsection{Static data study}

Before stripping, the strength of concrete was found to be $\approx 30 \mathrm{MPa}$. In the course of stripping, the deflection of the spherical part of the shell was measured (Chizanishvili took part in this experiment) [3]. The curve of vertical deflection corresponding to the loading from self-weight, based on the numerical calculations of the general theory of shells, is shown (Fig. 4). The curve of deflection, obtained by experimental methods, is represented by a dotted line. The experimental deflection values are marked by a bar.

Fig. 4 shows that the directions of both experimental and theoretical deflection coincide qualitatively. The obtained relative experimental and theoretical maximum values of the deflection from the diameter of the lower base $\left(\mathrm{W}_{\mathrm{e}} / 2 \mathrm{R}=1.41 / 2 * 10.87=1 / 15400\right.$ and $\mathrm{W}_{\mathrm{t}} / 2 \mathrm{R}$ $=1.73 / 2 * 10.87=1 / 12000$ ) show that there is high shell rigidity, which may contribute to structures' high earthquake resistance.

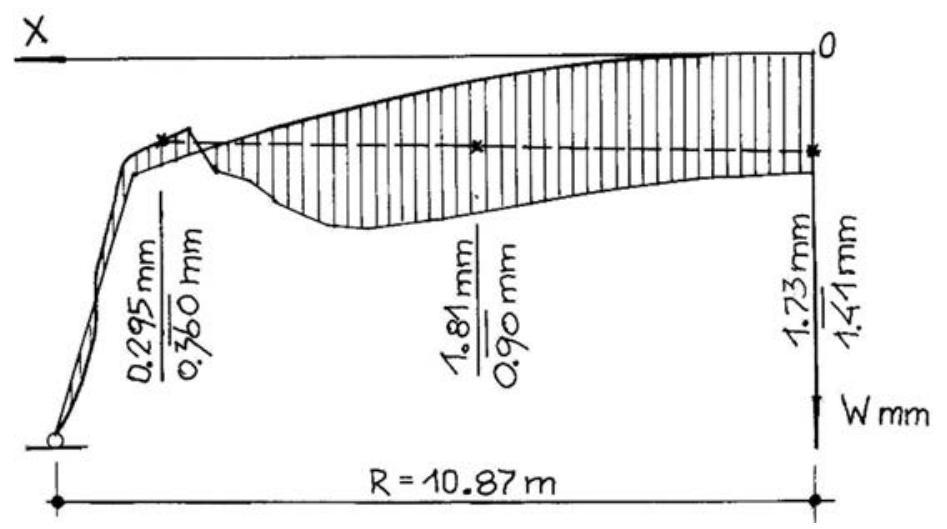

Figure 4: Schematic meridian section. The curve of vertical theoretical (" - " continuous line) and experimental deflections (" -- -- " dotted line). 


\subsubsection{Study of dynamic characteristics}

The dynamic characteristics of the shell were examined experimentally (Zaalishvili took part in the experiment) [13]. Oscillations were excited by vertical pulses concentrated in the shell center (each pulse of $3.5 \mathrm{Kn} / \mathrm{m}^{2}$ ). In doing so, vertical free oscillations of the shell were recorded with the aid of a H338-6П graph plotter and VEGIK vibration detectors installed on the shell surface. As a result of analyzing the oscillograms, a three-half-wave form of lowtone free oscillations across the shell diagonal section and frequency $f=14.28 \mathrm{~Hz}$, period $\mathrm{T}$ $=0.07 \mathrm{sec}$ and logarithmic decrement $\lambda=0.22$ were found [14].

\section{PRECAST-MONOLITHIC DOUBLE CURVATURE SHELL COVER IN SUKHUMI}

\subsection{Structure of shell}

A monolithic spherical precast reinforced concrete shell, covering a rectangular area, overlaps the central hall of the new market, erected in the city of Sukhumi (Fig. 5) [4]. In the plan, shell dimensions are $40 \times 40 \mathrm{~m}$, the surface is spherical and the rise is $7.6 \mathrm{~m}$ (Fig. 5). The main part of the roof, confined in the plan by a circle of $40 \mathrm{~m}$ in diameter, comprises two rows of precast reinforced concrete ribbed plates with inflexions near the ring ribs and subsequent embedment of joints between these ribs.

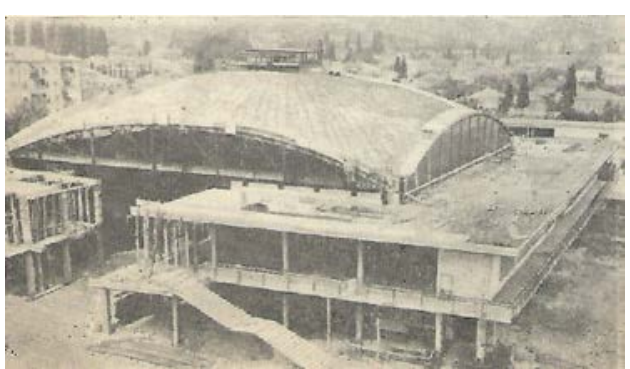

(a)

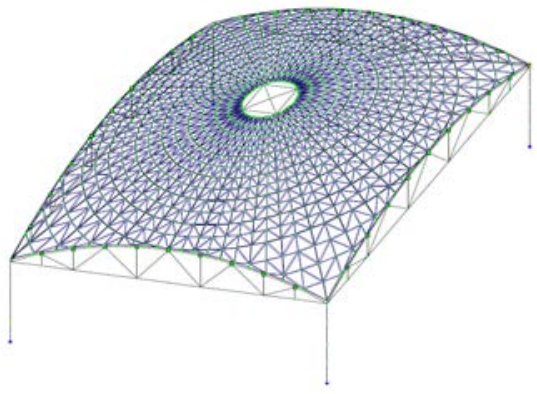

(b)

Figure 5: Building for the market. (a) General view; and (b) View of the design model.

The dome drum is $6 \mathrm{~m}$ in diameter and reinforced with radial beams; angular zones and contour band are made of monolithic concrete. Contour diaphragms are made of steel trusses which transmit the load to monolithic reinforced concrete columns that are $9.5 \mathrm{~m}$ in height and $90 \times 90 \mathrm{~cm}$ in cross-section (Fig. 5). Plate thickness of the monolithic portion is $10 \mathrm{~cm}$ near the band and $8 \mathrm{~cm}$ near the precast plates; the height of plate ribs is $30 \mathrm{~cm}$. The contour band, whose height is $35 \mathrm{~cm}$, is reinforced by a continuous three-dimensional (3D) cage over the entire contour of the shell, forming a closed band for the shell and welded to the upper band of the contour steel trusses, whose support parts are also welded.

\subsection{Structural analysis}

\subsubsection{Static study}

The design grade of concrete of the precast plates, monolithic sections, and the concrete for filling joints between the plates and columns, is M30. The roof design is based on the membrane theory of shells with a boundary effect for design load of $4 \mathrm{kN} / \mathrm{m}^{2}$ [15]. The critical 
load for stability, according to the Russian publication Instruction Manual on Design of the Reinforced Concrete Space Coverings and Floor Structures [15], is $6.0 \mathrm{kN} / \mathrm{m}^{2}$, and the limit load $5.4 \mathrm{kN} / \mathrm{m}^{2}$, in compliance with the theory of limit analysis according to Akhvlediani [16]. The building is designed for a seismic effect of horizontal acceleration of $\boldsymbol{a}_{h, \max }=0.75$ $\mathrm{m} / \mathrm{s}^{2}$ for the ground. Vertical displacement of the structure due to applied static loads (weight $300 \mathrm{~kg} / \mathrm{m} 2$ ) reached $27.3 \mathrm{~mm}$ for the trusses, $25.2 \mathrm{~mm}$ for the apex of the shell, and $0.54 \mathrm{~mm}$ for the columns; and the corresponding horizontal displacement of trusses at zones near the columns reached $+/-6.24 \mathrm{~mm}$. Maximum horizontal displacement at the top of columns was similar in both main horizontal directions, $+/-5.85 \mathrm{~mm}$.

\subsubsection{Study of the dynamic characteristics}

The dynamic characteristics were estimated both by analytical and numerical analysis. Dynamic characteristics of natural oscillations, determined by the analytic method [11], were as follows: frequency $f=18.86 \mathrm{~Hz}$, period $T=0.053 \mathrm{~s}$. The first modes of vibrations for the reviewing shell were caused by shell horizontal displacement (mainly due to bending of the columns): $T_{1 \text { (hor) }}=0.717 \mathrm{~s} ; T_{2 \text { (hor) }}=0.305 \mathrm{~s}$. Vibrations in a vertical direction were obtained for periods of $0.304 \mathrm{~s}$ and $0.21 \mathrm{~s}$, and smaller. Apparently, just higher modes of shell vertical vibrations were measured during the dynamic loading of the shell [4]: $\left(\mathrm{f}_{1}\right.$, test $=8 \mathrm{~Hz}$; or $T$, test $=0.125 \mathrm{~s})($ Table 2$)$. The three modes $(\# \# 1,9,45)$ of natural vibrations for these forms of the market building are shown in Fig. 6.

Table 2: Main results of the structural analysis on the market building: Maximum values. Earthquake direction: horizontal and vertical.

\begin{tabular}{|c|c|c|c|c|}
\hline \multirow{2}{*}{ Parameters } & \multicolumn{3}{|c|}{$\begin{array}{l}\text { Seismic loads. } \\
\text { Earthquake direction: vertical }\end{array}$} & \multirow{2}{*}{$\begin{array}{l}\text { Experiment } \\
\text { vertical }\end{array}$} \\
\hline & $\begin{array}{c}\text { Mode } 1 \\
\text { horizontal }\end{array}$ & $\begin{array}{l}\text { Mode } 9(1) \\
\text { vertical }\end{array}$ & $\begin{array}{c}\text { Mode } 45 \\
\text { vertical }\end{array}$ & \\
\hline $\begin{array}{l}\text { Periods of natural vibrations, } \mathrm{s} \text { : } \\
T_{1}=0.1688 ; T_{2}=0.1416 \\
T_{3}=0.1388\end{array}$ & 0.717 & $\begin{array}{c}0.304 \\
(0.213)\end{array}$ & 0.139 & 0.125 \\
\hline Base force $\mathrm{F}(\mathrm{h}, \mathrm{z}), t$ & 27.1 & 27.1 & 0.62 & \\
\hline $\begin{array}{l}\text { Max. displacement, mm } \\
\text { Vertical, w } \\
\text { Horizontal, u }\end{array}$ & $\begin{array}{l}1.940 \\
0.434\end{array}$ & $\begin{array}{l}1.94 \\
0.434\end{array}$ & $\begin{array}{l}0.044 \\
0.011\end{array}$ & \\
\hline $\begin{array}{c}\text { Maximum stress, MPa } \\
\sigma_{\mathrm{Ny}}(+) / \sigma_{\mathrm{Ny}}(-) \\
\sigma_{\mathrm{My}}(+) / \sigma_{\mathrm{My}}(-)\end{array}$ & $\begin{array}{l}0.210 / 0.160 \\
0.083 / 0.072\end{array}$ & & & \\
\hline
\end{tabular}

\subsection{Full-scale experiment}

\subsubsection{Static study}

When stripping the shell from the scaffolds, the strength of the concrete of the shell roof elements was determined using a cube crushing test and reference hammer within 30 to 40 $\mathrm{MPa}$. In the process of striking of the shell, deflection of the shell and contour diaphragm 


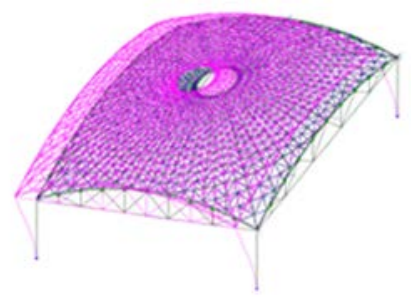

(a)

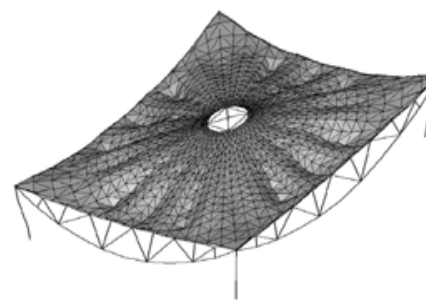

(b)

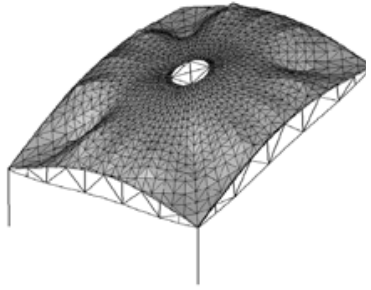

(c)

Figure 6: The modes of the market building's natural vibrations. (a) Mode shape 1 (Ed: horizontal); (b) Mode shape 1 (Ed: vertical); and (c) Mode shape 25 (Ed: vertical).

trusses' flex were measured (Fig. 5), as well as the horizontal and vertical movements of the support joints of the contour diaphragm trusses [15]. The location of deflection meters made it possible to control the uniform activation of all parts of the shell. Maximum deflection from self-weight in the shell center was equal to $27 \mathrm{~mm}$, with $20 \mathrm{~mm}$ at the middle of the truss span. Relative values of these deflections $\left(\mathrm{W}_{\mathrm{sh}} / \mathrm{L}=2.7 / 4000=1 / 1480\right.$ and $\mathrm{W}_{\mathrm{tr}} / \mathrm{L}=2.0 / 4000$ $=1 / 2000)$ bear record to sufficient rigidity of the shell and contour diaphragm trusses. Vertical movements of the support joints of the diaphragm trusses reached $1 \mathrm{~mm}$ and the divergence of the support joints in the plane of a diaphragm truss was $13.65 \mathrm{~mm}$, which corresponds to the tensile strength in the lower band: $72 \mathrm{MPa}$. This value is approximate to the design stress from the shell's self-weight as determined according to a previous study [15], which is $94 \mathrm{MPa}$. No cracks or other local defects were detected after the removal of the supporting scaffolding.

\subsubsection{Study of the dynamic characteristics}

The dynamic characteristics of the shell were examined experimentally [4]. Oscillations were excited by making vertical and horizontal pulses concentrated in the shell center (by sudden removal of a load of $500 \mathrm{~kg}$ ). Vertical free oscillations of the shell were recorded with the aid of a H338-6П graph plotter and VEGIK vibration detectors installed on the shell surface.

As a result of analyzing the oscillograms, we obtained a three-half-wave of the form of low-tone free oscillations across the shell's diagonal section, with a frequency $f=8 \mathrm{~Hz}$ and logarithmic decrement $\lambda=0.15$ [4], [14]. The value of the frequency obtained approximates the theoretical value $(f=9.8 \mathrm{~Hz})$ for monolithic shells as determined according to Oniashvili [11], yet it exceeds the experimental values of frequency $f$ given in Danieli [1] for similar precast shells, by $30 \%$ on the average. As a result of the tests, it was established that the degree of concrete embedding of a precast-monolithic shell is sufficiently high, which is indicative of its seismic stability.

\section{TRIANGULAR REINFORCED CONCRETE MONOLITIC SHELL}

\subsection{Structure of the shell}

The roof of a pump room in Borjomi, Georgia, was built in 1967 (Fig. 7(a)) [5]. The roof was made of monolithic reinforced concrete, the spherical shell is triangular in shape, and it is supported in the corners on points. The shell is bordered by three bowstring arches on the contour, connected among themselves in the support (Fig. 7(b)). The distance between the 
supports is $24.4 \mathrm{~m}$, the rise of the shell is $\mathrm{f}=8.0 \mathrm{~m}$ and of the arch is $\mathrm{f}_{0}=6.8 \mathrm{~m}$. Shell thickness $\mathrm{t}$ varies: In the center, shell thickness is $6 \mathrm{~cm}$, yet it reaches $10 \mathrm{~cm}$ near the contour elements. The dimensions of the cross-section of the arch are $30 \times 40 \mathrm{~cm}$. The pump room building was designed based on the membrane theory of shells and the theory of the limit analysis on the basis of the three-parameter mechanism of plastic collapse [5], [10]. The design grade of the concrete is M 30 .

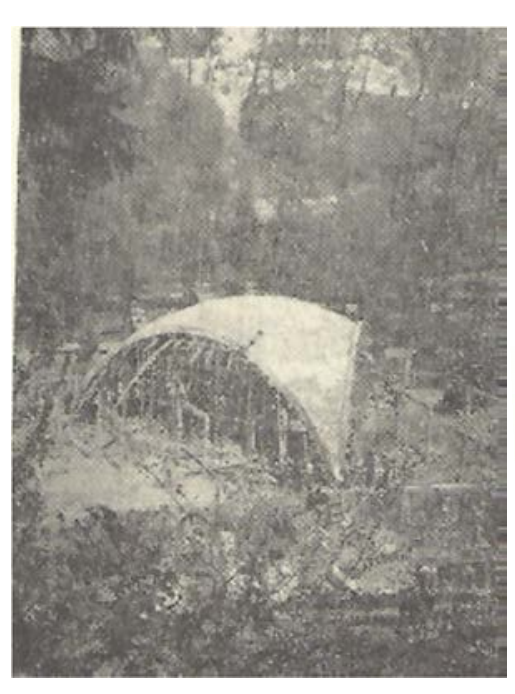

(a)

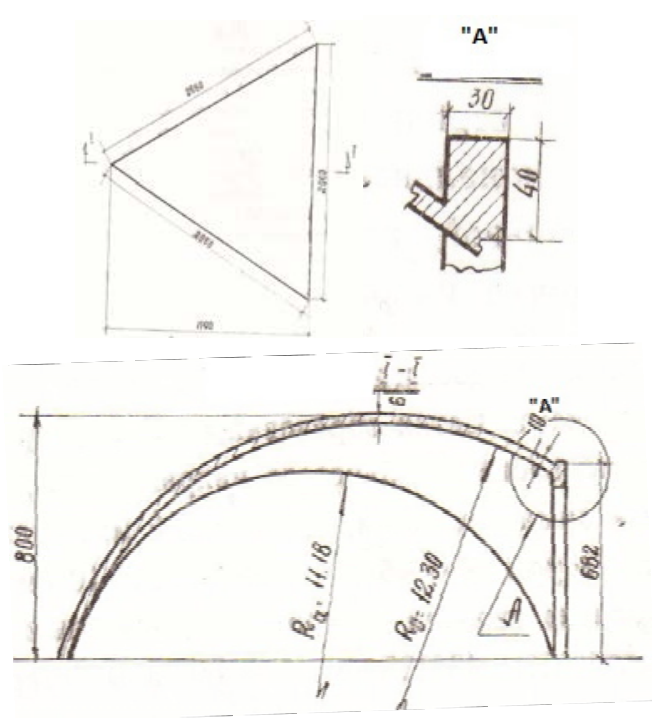

(b)

Figure 7: The roof of the pump room in the Borjomi. (a) General view; and (b) Design model.

\subsection{Numerical structural analyses}

Loads and masses were taken from past literature [5].

\subsubsection{Static analysis}

Maximum vertical displacement of the structure due to applied $300 \mathrm{~kg} / \mathrm{m}^{2}$ static loads reached $9.29 \mathrm{~mm}$ for the apex of the shell. The corresponding maximum horizontal displacement is $7.14 \mathrm{~mm}$ for the $X$ direction and $5.21 \mathrm{~mm}$ for the $Y$ direction. Maximum internal forces, normal and bending stress in the reinforced concrete shell elements were as follows: at the body of the shell: normal stresses $\sigma_{\mathrm{x}}=-4.0 \div 6.0 \mathrm{~kg} / \mathrm{cm}^{2}, \sigma_{\mathrm{y}}=-5.0-6.5 \mathrm{~kg} / \mathrm{cm}^{2}$ (by most area: $80 \%), \sigma_{\mathrm{xmax}}=-12.2 \mathrm{~kg} / \mathrm{cm}^{2}$ in local corner areas: $\sigma_{\mathrm{x}}=+1.2 \div 1.5 \mathrm{~kg} / \mathrm{cm}^{2}, \sigma_{\mathrm{y}}=2.0 \mathrm{t} / \mathrm{m}^{2}$. Bending moments in the corner areas were: $M_{x \max }= \pm 0.38 \mathrm{t}^{*} \mathrm{~m} / \mathrm{m}, \mathrm{M}_{\mathrm{y}}=\div 0.32 \div 0.40 \mathrm{t} * \mathrm{~m} / \mathrm{m}$, $\mathrm{t} / \mathrm{m}^{2} \sigma_{\operatorname{mxmax}}= \pm 3.0 \mathrm{t} / \mathrm{m}^{2}$; and $\sigma_{\operatorname{mymax}}= \pm 2.52 \div 3.75 \mathrm{t} / \mathrm{m}^{2}$. Maximum internal forces in the contour bordered arches: axial forces: $\mathrm{N}_{\max }=-22.3 \mathrm{t}$; normal stress $\sigma=18.58 \mathrm{~kg} / \mathrm{cm}^{2}$. In the corner zones $-\mathrm{M}_{\mathrm{ymax}}= \pm 3.7 ;-2.7 \mathrm{t}^{*} \mathrm{~m} ; \mathrm{M}_{\mathrm{zmax}}= \pm 2.7 \mathrm{t} * \mathrm{~m} ; \sigma_{\mathrm{ymax}}= \pm 0.462 \mathrm{~kg} / \mathrm{cm}^{2}$. Axial forces in the steel ties - bars (profile - cross- section UPB N140) $\mathrm{N}=6.7 \div 6.9$ t. The three modes $(3,7,9)$ of natural vibrations for these forms of the pump room roof are shown in Fig. 8. The displacement, contour of normal stress and bending moments for these forms of the pump room roof are shown Table 3 . 


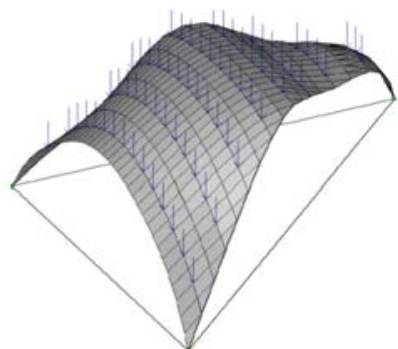

(a)

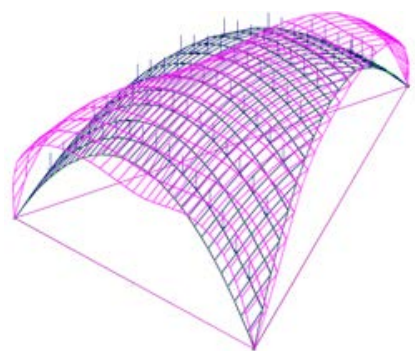

(b)

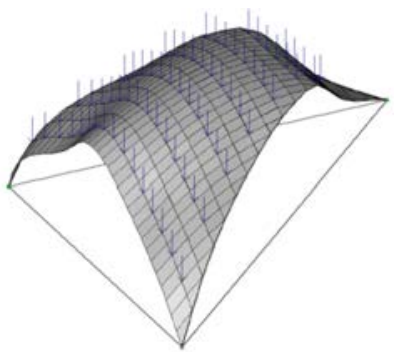

(c)

Figure 8: The mode shapes of the cover of pump room. Ed: (a) Mode shape 3 (Ed: vertical); (b) Mode shape 7 (Ed: vertical); and (c) Mode shape 9 (Ed: horizontal).

Table 3: Main results of structural analysis for the Pump room roof. Maximum values. Earthquake directions: horizontal and vertical.

\begin{tabular}{|c|c|c|c|c|}
\hline \multirow[t]{2}{*}{ Parameters } & \multicolumn{3}{|c|}{$\begin{array}{l}\text { Seismic loads. } \\
\text { Earthquake direction: vertical }\end{array}$} & \multirow{2}{*}{$\begin{array}{l}\text { Experiment } \\
\text { vertical }\end{array}$} \\
\hline & Mode 3 & Mode 7 & Mode 9 & \\
\hline $\begin{array}{l}\text { Periods of natural vibrations } \\
\text { (s) }\end{array}$ & 0.175 & 0.067 & 0.049 & 0.2 \\
\hline Base force $\mathrm{F}(\mathrm{h}, \mathrm{z}), t$ & 1.15 & 1.13 & 0.96 & \\
\hline $\begin{array}{l}\text { Max. displacement, } \mathrm{mm} \\
\text { Vertical, } \mathrm{w} \\
\text { Horizontal, } \mathrm{u}_{\mathrm{x}-\mathrm{x}} \\
\quad \mathrm{u}_{\mathrm{y}-\mathrm{y}}\end{array}$ & $\begin{array}{l}0.703 \\
0.515 \\
0.396\end{array}$ & $\begin{array}{l}0.103 \\
0.069 \\
0.099\end{array}$ & $\begin{array}{l}0.052 \\
0.048 \\
0.022\end{array}$ & \\
\hline $\begin{array}{c}\text { Maximum stress (Mpa) } \\
\sigma_{\mathrm{Ny}}(+) / \sigma_{\mathrm{Ny}}(-) \\
\sigma_{\mathrm{My}}(+) / \sigma_{\mathrm{My}}(-) \\
\end{array}$ & $\begin{array}{l}0.210 / \\
0.160\end{array}$ & & & \\
\hline
\end{tabular}

\subsection{Full-scale experiment}

\subsubsection{Static study}

In the process of striking the shells, vertical deflections in the planes of median of the triangle and contour bordered arch from the self-weight of the shell, formwork and support scaffolding of shell were measured $\left(\mathrm{q}=2.5 \mathrm{kN} / \mathrm{m}^{2}\right)$. In Fig. 9 , the vertical experimental is represented by a continuous line and the theoretical deflections are represented by a dotted line. Maximum deflection in the shell in the planes of the median of the triangle and contour-bordered arches were $\mathrm{W}_{\mathrm{m}}=16.81 \mathrm{~mm}$ and $\mathrm{W}_{\mathrm{a}}=6.91 \mathrm{~mm}$, respectively. The relative values of these deflections, $\mathrm{W}_{\mathrm{m}} / \mathrm{R}_{\mathrm{c}}=1.681 / 1200=1 / 715$ and $\mathrm{W}_{\mathrm{a}} / \mathrm{R}_{\mathrm{c}}=0.691 / 1200=1 / 1740$, indicate there is sufficient rigidity of the shell and contour bordered arches. No cracks or other local defects were detected after the removal of the supporting scaffolding.

\subsubsection{Study of the dynamic characteristics}

The dynamic characteristics of the shell were examined experimentally [2], [14]. Oscillations were excited by a horizontal acting load concentrated in the shell corner. In doing so, the 
vertical free oscillations of the shell were recorded with the aid of a H338-6П graph plotter and VEGIK vibration detectors that were installed on the shell surface. Based on an analysis of the oscillograms, we found a frequency $f=5 \mathrm{~Hz}$ and logarithmic decrement of $\lambda=0.1$.

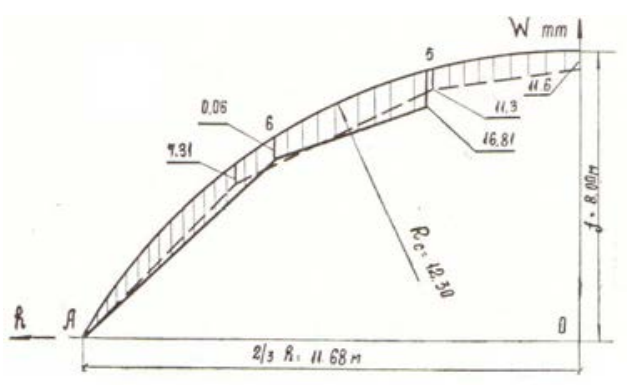

(a)

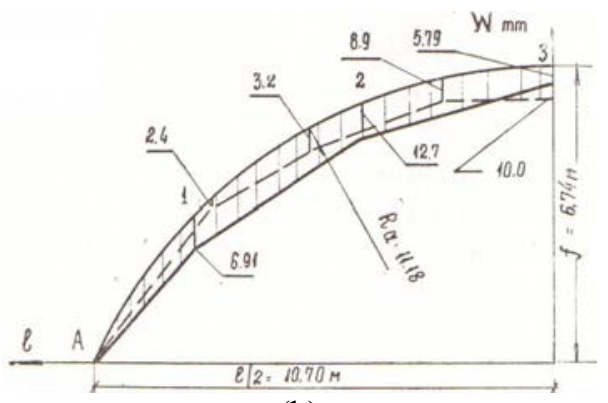

(b)

Figure 9: The curve of the vertical experimental (continuous line) and theoretical deflections (dotted line) in the planes of (a) the median of the triangle; and (b) the contour bordered arch.

\section{CONCLUSIONS}

1. Shells of double positive curvature are very rigid. Therefore, in approximate calculations it is possible for horizontal vibrations to simulate a hard disk. Durations of vibrations for such structures are durations of vibrations for their supporting structures (see the shell in Sukhumi, for example). Durations for vertical vibrations for this type of shells are low: $0.15-0.20 \mathrm{~s}$.

2. The major part of the shell $(80-85 \%)$ is in compression in both directions. Corresponding reinforcement can be minimal, as normal stress due to bending moments is low. Local edge zones (for example, especially the shell in Borjomi) and local zones with significant geometric changes (for example, see the shell in Karatchaevsk), normal stress of bending moments is significant. Consequently, corresponding dimensions of contour elements and their reinforcement and additional reinforcement of local zones of the shell body is necessary.

3. Similar problems are typical of the shells of ancient architecture in the East, although shell buckling does not typically occur as the spans are not so large. Massive walls are able to carry tension and bending due to significant weight and section dimension; however, attempts to open holes in these walls leads to a reduction in the wall loadcarrying capacity, which might become dangerous even for existing load levels.

4. All three constructions were shown to have the required seismic resistance; however, shells with stiffer and more rounded contours were found to exhibit better seismic behavior.

5. Alternative solutions for supporting shell areas may include the use of ties (see the shell in Borjomi) or bottom joists of the trusses (see the shell in Sukhumi).

\section{REFERENCES}

[1] Danieli, M., Construction of precast concrete shells in Georgia. Earthquake Resistant Engineering Structures XI, 97, pp. 149-160, 2017.

[2] Akhvlediani, N. et al., Investigation, design, and construction of aseismic spatial structures based on the theory of limit equilibrium. Proceedings of the International 
Congress of IASS Theoretical and Experimental Studies of Spatial Structures: The Use of Shells in Civil Engineering, pp. 190-201, 1985.

[3] Danieli (Danielashvili), M., Limit analysis of reinforced concrete shells of revolution and its application. Proceedings of the Ninth International Conference on Civil and Structural Engineering Computing, B.H.V., pp. 1-20, 2003.

[4] Akhvlediani, N. et al., Shell roof for market in Sukhumi-town. Concrete and Reinforced Concrete, 10, pp. 6-7, 1983 [in Russian].

[5] Akevlediani, N. et al., Investigation of the carrying capacity of hoisting concrete shells of double curvature on three supporting points. Structural Mechanics of Spatial Structures, 4, pp. 39-49, Metsniereba, Tbilisi [in Russian].

[6] Akhvlediani, N. \& Danielashvili, M., Limit analysis of reinforced concrete shells of revolution. Archiwum Inzynerii Ladowey, Polska Akademia Nauk, XXXVI, Z-3, pp. 187-205, 1990.

[7] Richard, N. et al., International symposium on ultra-high performance fiber-reinforced concrete. RILEM Symposium, 2013.

[8] Fragonara, L.Z., Dynamic Models for Ancient Heritage Structures. Doctoral Thesis, Politecnico di Torino: Italy, 2012.

[9] ter Maten, R.N., Ultra-High Performance Concrete in Large Span Shell Structures. Master's Thesis, Delft University of Technology, Structural and Building Engineering, Delft: The Netherlands, p. 313, 2012.

[10] Hosseini, M., Hajnasrollah, S. \& Herischian, M., A comparative study on the seismic behavior of ribbed, Schwedler and diamatic space domes by using dynamic analysis. Proceedings of the 15th World Conference of Earthquake Engineering, pp. 3022230231, 2012.

[11] Oniashvili, O., Some Dynamic Problems of the Theory of Shells, USSR Academy of Sciences: Moscow, p. 320, 1957.

[12] Danieli, M., Bloch, J. \& Halperin, I., Analysis of seismic stability of shells of revolution using probabilistic methods. Earthquake Resistant Engineering Structures VIII, WIT Press: Southampton and Boston, pp. 249-260, 2011.

[13] Danielashvili, M., Katsapchuk, K. \& Melnik-Melnikov, P., Probabilistic analysis of the seismic stability of concrete shells of revolution. Spatial Structures of Buildings and Edifices, Belgorod: Moscow, pp. 5-12 [in Russian].

[14] Danielashvili, M. \& Zhorzholadze, T., Experimental and theoretical studies of the dynamic characteristics of shells. Proceedings of the International Conference on Applied Mechanics, pp. 1733-1738, 1989.

[15] Instruction manual on design of the reinforced concrete space coverings and floors structures, Stroiizdat: Moscow, p. 320, 1979 [in Russian].

[16] Akhvlediani, N., On calculation the load carrying capacity of shallow reinforced concrete shells of dual curvature. Studies of the Theory of Structures, 2, pp. 78-86, 1962 [in Russian]. 